\title{
Spatial structure optimization of mountainous abandoned mine land reuse based on system dynamics model and CLUE-S model
}

\author{
Linlin Cheng $^{1} \cdot$ Haiyuan Sun ${ }^{1} \cdot$ Ye Zhang $^{1} \cdot$ Shaofeng Zhen $^{1}$
}

Received: 30 December 2018/Revised: 20 January 2019/Accepted: 23 February 2019/Published online: 4 March 2019

(C) The Author(s) 2019

\begin{abstract}
The mountainous abandoned mine land is often distributed in the form of fragmented patches. Therefore, it can greatly promote the reuse value of abandoned mine land and relieve the pressure of land demand to realize the rational reuse of abandoned mine land based on the future land use structure and spatial layout of mountainous area. In this paper, optimization of the spatial structure of mountainous abandoned mine land reuse is realized through the system dynamics model and CLUE-S model. Mentougou district, Beijing, China is selected as the research area. System dynamics model with feedback functions is constructed to simulate land use structure from 2011 to 2025 , which is taken as the quantitative constraint on spatial structure optimization. CLUE-S model with neighborhood analysis function is applied to simulate future land use spatial structure. The simulation result layer is superimposed with the abandoned mine land distribution layer and the optimized spatial structure of abandoned mine land reuse then is determined, checked by reuse suitability evaluation. The result shows that abandoned mine land can be fully optimized as other land use types according to demand, and the reuse directions are water conservancy facilities land, urban land, rural residential land, tourism land, garden land, woodland and grassland. The trend of abandoned mine land reuse tend to be consistent with land use types of neighboring patches. This study can provide theoretical reference for the practices of mountainous abandoned mine land reuse.
\end{abstract}

Keywords Mountainous abandoned mine land - Reuse - System dynamics model · CLUE-S model $\cdot$ Spatial structure optimization

\section{Introduction}

Although mineral exploitation has brought tremendous momentum for economic and social development, various forms of abandoned mine land are generated in the meantime (Cheng and Skousen 2017; Li 2006). In 2016, China's annual non-oil gas mineral production reached 7.601 billion $t$, and the estimated related newly damaged land was more than $4200 \mathrm{hm}^{2}$. The global output of raw coal alone reached 7.46 billion $\mathrm{t}$, and the estimated newly

Linlin Cheng

chll@cumtb.edu.cn

1 College of Geoscience and Surveying Engineering, China University of Mining and Technology (Beijing), D11 Xueyuan Road, Haidian District, Beijing 100083, China damaged land related to raw coal mining reached more than $4300 \mathrm{hm}^{2}$ (National Bureau of Statistics 2017; Liang 2018). Therefore, a lot of practice activities have been carried out on the reuse of abandoned mine land at home and abroad. Seattle Gasworks Park in the United States, Lake Park in Britain and Kotbuss, Open-pit Mine in Germany are precedents for the reuse of abandoned mine land (Holden 1999; McHarg 2006; Weilacher 1999). Tangshan Nanhu Park, Fushun West Open-pit Mine Forest Park and Hubei Huangshi National Park in China are also successful cases (Shi 2013; Li et al. 2013).

However, the existing practices mostly focused on abandoned mine land distributed contiguously, but rarely involve the reuse of scattered patches of abandoned mine land in mountainous area. Land resources in mountainous areas are scarce. Therefore, it can greatly promote the reuse value of abandoned mine land and relieve the pressure of 
land demand in mountainous area to a certain extent by integrating the reuse of fragmented abandoned mine land into land use planning, combined with the future land use structure and spatial layout of mountainous region.

Scholars at home and abroad mostly use models to study future land use structure and spatial distribution. Trend extrapolation method, Markov model and system dynamics model are commonly used models for land use structure prediction (Mishra and Rai 2016; Naboureh et al. 2017; Wu et al. 2017; Zhai et al. 2018; Zhao et al. 2016). Trend extrapolation method is a kind of extrapolation prediction that realized by finding a suitable function to reflect the trend of change according to the rising or falling trend of the predicted object with no situation of sudden change (Huang and Zhao 2011). Markov model uses the transition probability matrix between different states to predict the state of event occurrence and its development trend, but its prediction error for long-term event is large ( $\mathrm{Li} \mathrm{2012;}$ Nobre Neto et al. 2018). System dynamics model considers that the object is composed of many subsystems, and there are dynamic interactions among subsystems and the structure, function and behavior of each element, thus making the whole system to be a feedback system which is suitable for simulating the behavior characteristics of nonlinearity, multi-variable, multi-loop and complex timevarying (Wang 2009). Optimization and allocation models of land spatial layout include cellular automata (CA) model, Dinamica EGO model and CLUE-S model (Gidey et al. 2017; Jahanishakib et al. 2018; Mehdi et al. 2018; Qi et al. 2018; Olmedo et al. 2018). CA model has characteristics of strong self-organizing, and it simulates complex spatial structure by simple local raster transformation according to model rules. It has natural advantages in human social system modeling (Al-sharif and Pradhan 2014; Gharbia et al. 2016; Mao et al. 2013). Dinamica EGO model estimates transformation probability based on Bayesian principle, and simulates land use spatiotemporal dynamic change based on CA model principle (Olmedo et al. 2018; Gao and Yi 2012). CLUE-S model dynamically simulates the spatial distribution of land use types in the future according to the competition relationship which results from quantifying the driving factors and the land use type of each pixel and its neighborhood (Liu et al. 2014; Mehdi et al. 2018; Waiyasusri et al. 2016). In general, land use structure prediction models can predict the quantity change, but it is difficult to reflect the spatial change. The spatial layout optimization models have strong ability for spatial prediction, but weak ability to explain the time change of land use structure. Therefore, it can effectively predict the spatial and temporal dynamic changes of land use by integrating the advantages of land use structure prediction model and spatial layout optimization model, and giving full play to the characteristics of various models.

The spatio-temporal dynamic change of land use is the driving result of many factors such as climate, environment, social economy and population policies (Song et al. 2018), and its evolution process is characterized by nonasymptotic and complex feedback. Therefore, the system dynamics model with nonlinear, multi-variable, multi-loop and complex time-varying feedback system can be selected to simulate the changing trend of medium or long term land use structure (Grossler et al. 2018; Tian et al. 2016; Wang 2009; Wu et al. 2017). Meanwhile, abandoned mine land in mountain areas has the characteristics of scattered distribution, and its reuse is more susceptible to land use types of adjacent patches, so the CLUE-S model with the function of neighborhood analysis should be selected to simulate and optimize the spatial layout of land use in the future (Gao and Yi 2012; Liu et al. 2014; Mehdi et al. 2018; Waiyasusri et al. 2016; Wu et al. 2015; Zhou et al. 2016). Taking Mentougou District of Beijing, China as the study area which is mainly consisted of mountainous areas and has a great quantity of idle abandoned mine land, this paper simulates the change of land use structure and spatial distribution by coupling the system dynamics model and CLUE-S model to determine the reuse direction and spatial layout of abandoned mine land, checked by the results of reuse suitability evaluation. The aim is to provide theoretical support and reference for the reuse of abandoned mine land in mountain areas.

\section{General situation of study area and data sources}

Mentougou District is located at the southwest of Beijing, the capital of $\operatorname{China}\left(115^{\circ} 25^{\prime}-116^{\circ} 10^{\prime} \mathrm{E}, \quad 39^{\circ} 48^{\prime}-\right.$ $40^{\circ} 10^{\prime} \mathrm{N}$ ), at the junction of the North China Plain and Inner Mongolia Plateau, and up to $98.5 \%$ of the territory is mountain. By the end of 2015, it had a total area of 1 , $448.84 \mathrm{~km}^{2}$ with a permanent resident population of about 308,000 , and it was consisted of four streets and nine towns. As shown in Fig. 1, the whole altitude inclines from northwest to southeast.

Mineral resources in Mentougou District are mainly coal, followed by limestone, shale ore, basalt ore, slate and iron ore. Abandoned mine land formed by mineral exploitation is usually divided into three categories: abandoned occupied land, abandoned subsided land and abandoned excavated land. By 2014, there was $603.79 \mathrm{hm}^{2}$ of abandoned mine land in Mentougou District, which was distributed widely and scattered (see Fig. 1). Among them, the area occupied by coal gangue is $112.41 \mathrm{hm}^{2}$, accounting for $18.6 \%$ of the total area; the area occupied by rock and slag is $124.05 \mathrm{hm}^{2}$, accounting for $20.5 \%$; the area 


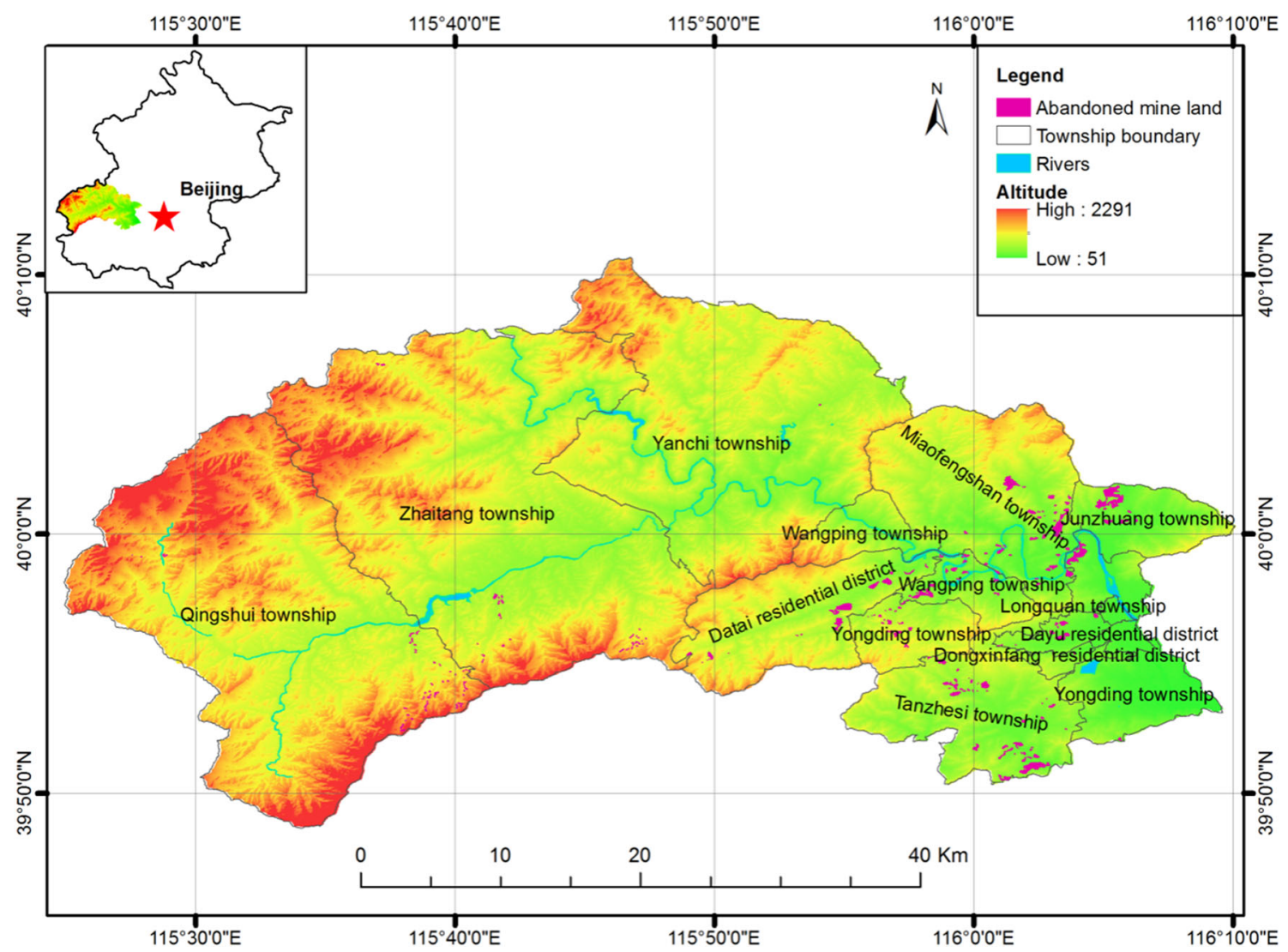

Fig. 1 Geographical position and distribution of abandoned mine land of Mentougou District

occupied by abandoned houses is $107.51 \mathrm{hm}^{2}$, accounting for $17.8 \%$; the area of abandoned excavated land is 245.71 $\mathrm{hm}^{2}$, accounting for $40.7 \%$, and abandoned subsided land is $14.11 \mathrm{hm}^{2}$, accounting for $2.3 \%$.

The main data involved in this paper include economic, social and land use data of Mentougou District from 2006 to 2020. The land use data were provided by the land department of Mentougou District, which mainly include the land use status data of Mentougou District in 2006, 2010 and 2015, the land use change data from 2006 to 2010, and the land-use planning data of Mentougou District and each town from 2006 to 2020. The statistical data are mainly derived from the Statistical Yearbook of Mentougou District, Beijing, which is used for quantitative analysis of social, economic, demographic and meteorological factors. The distribution and status data of abandoned mine land being occupied, subsided and excavated in the research area were determined based on remote sensing images and field survey. The data of reuse suitability evaluation of abandoned mine land were derived from the research project of public welfare industry of the Ministry of Land and Resources of China, which was done in Mentougou by the authors.

\section{Methodology}

System dynamics model and CLUE-S model are integrated to optimize the spatial structure of abandoned mine land reuse. The quantitative land use structure is predicted by system dynamics model according to regional land policy, land dynamic change characteristics and socio-economic factors, and the prediction results are taken as the constraints of spatial structure optimization. Abandoned mine land and other independent industrial and mining land are involved in the optimization process of the whole region by CLUE-S model. The spatial layout of abandoned mine land is then determined, checked by the reuse suitability evaluation.

\subsection{Establishment and verification of system dynamics model}

Based on land use classification system and the research purpose, land use of Mentougou is divided into four categories: independent industrial and mining land, other construction land, unused land and agricultural land. Other construction land includes traffic land, water conservancy facilities land, tourism land, other special land, urban land and rural residential land, and agricultural land is divided 
into grassland, garden land, woodland, cultivated land and other agricultural land. Other special land mentioned above mainly refers to the land for military facilities, embassies and consulates, religious activities, prisons and detention houses, funerals, etc., and other agricultural land is the land for field threshold and facilities.

Since the reform and opening-up, China's regional land use change has been mainly driven by economic factors and population factors ( $\mathrm{Gu}$ et al. 2017; $\mathrm{Lu}$ 2012). Therefore, the land use system can be divided into economic subsystem, population subsystem and land subsystem. According to the research purpose, this study took the supply-demand relationship of land use of Mentougou as the main line to select the main elements involved in the land use system and explore the mutual relationship of conversion and restriction among various land types and each subsystem. The causal relationships between the main elements are shown as follows: construction land occupies agricultural land; unused land is developed for construction land and agricultural land; the increase of total population promotes the expansion of the demand for construction land and agricultural land; urbanization leads to the expansion of construction land demand and promotion of unused land development; the growth of GDP, on the one hand, leads to the expansion of construction land demand and the promotion of unused land development, on the other hand, promotes the growth of fixed assets investment. Figure 2 shows the causal feedback relationship between subsystems and the main factors of the model. When polarity is positive $(+)$, it means that the changes of cause and result are in the same directions. When polarity is negative $(-)$, it means that the changes of cause and result are in the opposite directions.

The causal feedback diagram of the system dynamics model can only briefly describe the logical relationship among subsystems and main factors of the land use system, but cannot quantitatively describe the mutual relationship of conversion and restriction among elements. Therefore, it is necessary to further describe the development and changes of the system with the help of software and mathematical language based on the above causal feedback relationships, the analysis of the impact of social, economic and land policies on the function and structure of the land use system (Chen et al. 2017; Yang et al. 2006). In this paper, sixty-six variables including 19 state variables, 18 rate variables, 26 auxiliary variables, 2 regulatory variables and 1 constant were selected to build the system dynamic model of land use system in Mentougou District through Vensim PLE software, as shown in Fig. 3. The simulation period is from 2011 to 2025 in which 2011-2016 is the test and evaluation stage, and the simulation step is 1 year.

Accurate parameters are preconditions for the model to simulate reality. Methods of determining model parameters involved in this paper include land use type, temporary population, permanent population and GDP in 2010 determined by the collected land use status map and statistical yearbook; the growth rate of temporary population, permanent population and GDP calculated by trend extrapolation; land use and population policy determined according to historical data, relevant literature and expert experience; fixed-asset investment rate, per capita construction land and other parameters determined by multiple linear regression analysis, correlation analysis and logistic blocking growth model simulation. The final parameters are determined by repeated debugging according to the behavior characteristics of relevant parameters.

The fitting degree calculated by simulation data and historical data is adopted to test the model. The calculation formula is shown as follows:

$\varepsilon=\frac{x^{\prime}-x}{x} \times 100 \%$

where $\varepsilon$ is the fitting degree between historical data $x$ and predicted data $x^{\prime}$.

The results of test stage show that the simulation value of system dynamic model constructed in this paper fits well with the historical value (Table 1). The errors of most predicted values are less than $1 \%$, and the maximum error is less than $2 \%$, which means the relative error between model simulation value and historical value is within a reasonable range, and the model is reliable for real-world simulation (Xiong et al. 2018; Xu and Coors 2012).

In addition, the key parameters of the model, such as resident population, GDP, urbanization level, rural residential land, urban land, garden land and independent industrial and mining land, are selected to simulate the behavior of the system. The change value of each parameter in 2014 (decreased or increased by 5\%) is selected to run on the model, and sensitivity analysis is based on Formula 2 (Zhang et al. 2012):

$P=\frac{|[J(k-\Delta k)-J(k)] / J(k)|}{|\Delta k / k|}$

where $P$ is the degree of sensitivity; $k$ is a parameter; $\Delta k$ is the change amount of parameter $k ; J$ is the objective function value of parameter $k$.

When the variation of parameter is $5 \%$, the analysis results show that the maximum sensitivity degree is 0.55 , while the minimum is 0.0013 , and the average value is no more than 0.11 . The influence of the changes of various key parameters on the system is uneven, so it can be considered that the simulation of land use system dynamic model in Mentougou District is appropriate and effective (Chen et al. 2008). 


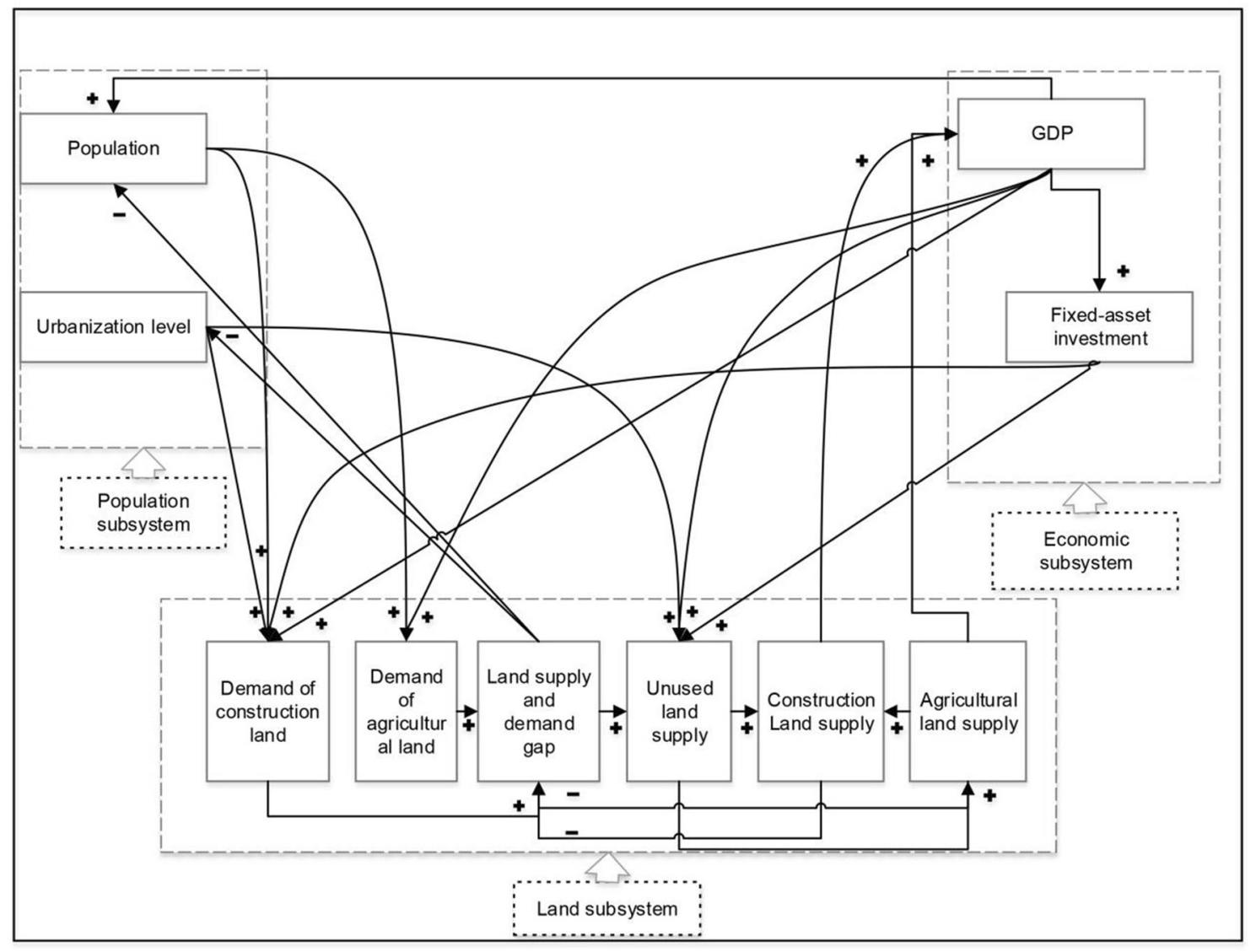

Fig. 2 Cause-and-effect feedback diagram of system dynamic model of land use system in Mentougou

\subsection{The construction of CLUE-S model}

CLUE-S model constructs empirical quantitative relationship based on the regional historical land use data and driving factor data, iteratively calculates the distribution probability of each land use type in each spatial pixel, and finally uses the system theory method to carry out the spatial distribution of land use types according to the probability of each raster pixel (Anputhas et al. 2016; Liu et al. 2014; Mohammady et al. 2018; Waiyasusri et al. 2016; Wei 2018; Zhang 2013; Zheng et al. 2012). After investigation and analysis, it was found that the diameter of the smallest patch on the map of abandoned mine land in Mentougou was $16.25 \mathrm{~m}$, and raster data of $15 \mathrm{~m}$ resolution could be used to construct CLUE-S model for simulation of land use pattern in 2025.

Driving force analysis is the theoretical basis and important tool to explain the formation and evolution of land use status. Regression analysis is usually used to analyze the statistical relationship between various land use types and driving factors (Li et al. 2012; Liu et al. 2014; Moulds et al. 2015; Zheng et al. 2012; Zhong 2011). In a short period, the driving capacity of natural factors on land use change is limited, but there will be obvious cumulative effect in a long time scale. However, the impact of social and economic activities plays a leading role in the largescale changes of land use which happened in a short term. According to the actual situation of the research area and the comprehensiveness, accuracy, availability and quantifiable description of driving factors, this paper selected 10 driving factors from the aspects of natural conditions and social economy: topographic factors (slope and altitude); distance factors (the closest distances from main road, town, village and water area to the abandoned mine land), the main roads includes railways, national roads, provincial roads, county roads and township roads, and the distance factor adopts Euclidean distance; socio-economic factors (urbanization level, population density and regional per capita GDP calculated by dividing township administrative regions into units); soil factor (soil fertility grade). ROC curve is usually used to evaluate and test the effect of driving force explanatory ability (Liu et al. 2014; Mohammady et al. 2018; Zhai et al. 2018). The larger the ROC value is, the better the regression analysis result is and the higher the accuracy is. After calculation, the ROC values of all land types in this paper are greater than 0.7, indicating that the 10 selected driving factors have good 


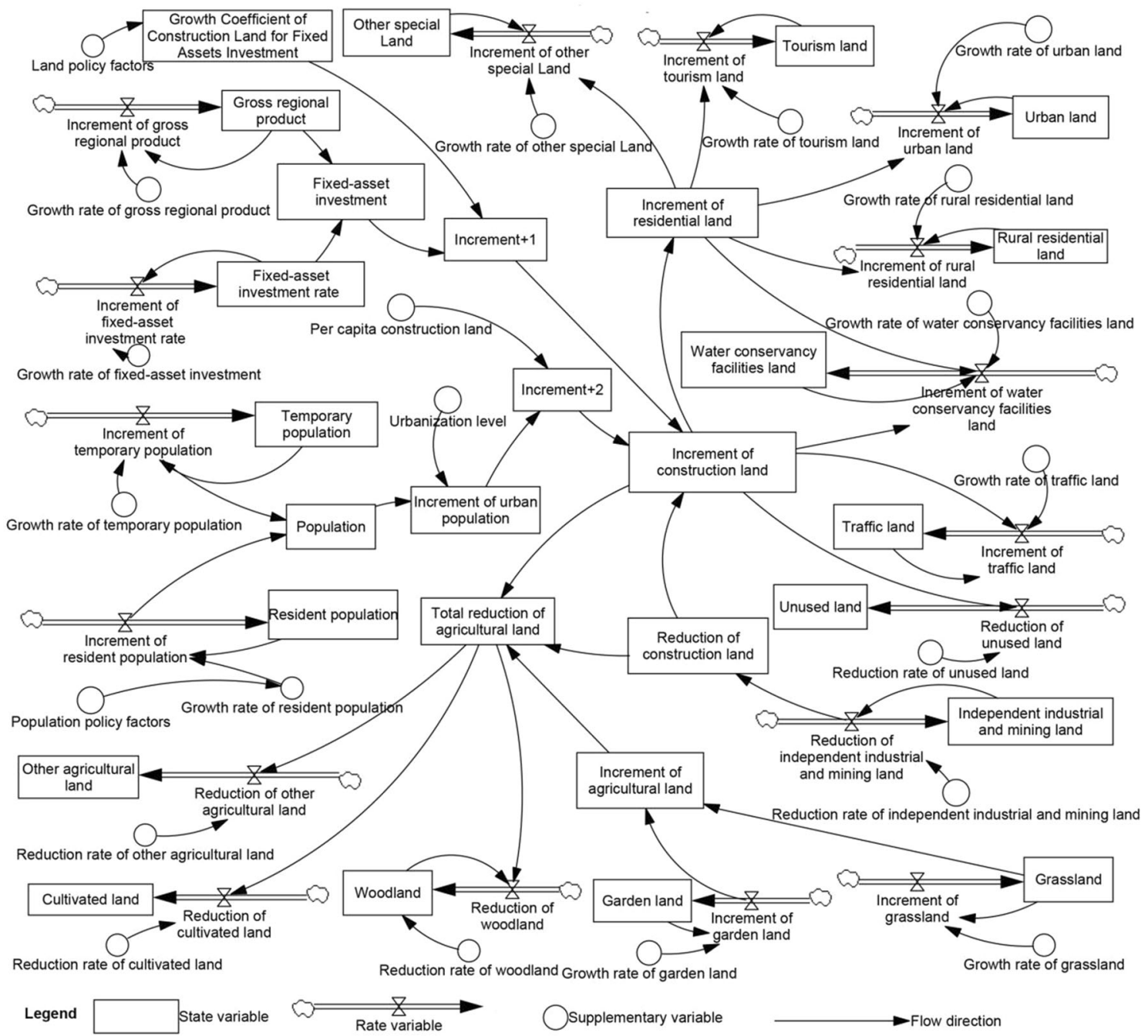

Fig. 3 Flow diagram of system dynamic model of land use system in Mentougou District

Table 1 Simulation errors of test stage (unit: $\mathrm{hm}^{2}$ )

\begin{tabular}{|c|c|c|c|c|c|c|c|c|c|}
\hline \multirow[t]{2}{*}{ Year } & \multicolumn{3}{|c|}{ Agricultural land } & \multicolumn{3}{|c|}{ Construction land } & \multicolumn{3}{|c|}{ Unused land } \\
\hline & $\begin{array}{l}\text { Simulation } \\
\text { values }\end{array}$ & $\begin{array}{l}\text { Actual } \\
\text { values }\end{array}$ & $\begin{array}{l}\text { Errors } \\
(\%)\end{array}$ & $\begin{array}{l}\text { Simulation } \\
\text { values }\end{array}$ & $\begin{array}{l}\text { Actual } \\
\text { values }\end{array}$ & $\begin{array}{l}\text { Errors } \\
(\%)\end{array}$ & $\begin{array}{l}\text { Simulation } \\
\text { values }\end{array}$ & $\begin{array}{l}\text { Actual } \\
\text { values }\end{array}$ & $\begin{array}{l}\text { Errors } \\
(\%)\end{array}$ \\
\hline 2011 & 9232 & 9240 & -0.09 & 128379.2 & 128184.8 & 0.15 & 7451.5 & 7361.1 & 1.23 \\
\hline 2012 & 9273.8 & 9370.7 & -1.03 & 128356.8 & 127979.4 & 0.29 & 7432.4 & 7485.9 & -0.04 \\
\hline 2013 & 9338.8 & 9459.8 & -1.27 & 128310.8 & 127902.7 & 0.24 & 7413.4 & 7323.5 & 1.23 \\
\hline 2014 & 9380 & 9400.5 & -0.22 & 128288.3 & 128028.9 & 0.2 & 7394.7 & 7356.7 & 0.52 \\
\hline 2015 & 9432.9 & 9415.7 & 0.18 & 128253.5 & 128016.4 & 0.19 & 7376.5 & 7354 & 0.31 \\
\hline 2016 & 9493.5 & 9541.7 & -0.51 & 128210.3 & 127994.6 & 0.25 & 7358.7 & 7349.7 & 0.12 \\
\hline
\end{tabular}

explanatory abilities for the land use pattern of Mentougou District.

Abandoned mine lands in Mentougou area distribute in small patches, while the neighborhood analysis function of CLUE-S model can fully consider the relationship between the reuse types of abandoned mine lands and land use types of adjacent patches. Neighborhood analysis takes full account of the self-aggregation of various land types and the mutual aggregation or exclusion characteristics of different land use types, which greatly improves the simulation accuracy. It mainly includes neighborhood enrichment factor calculation and neighborhood interaction factor 


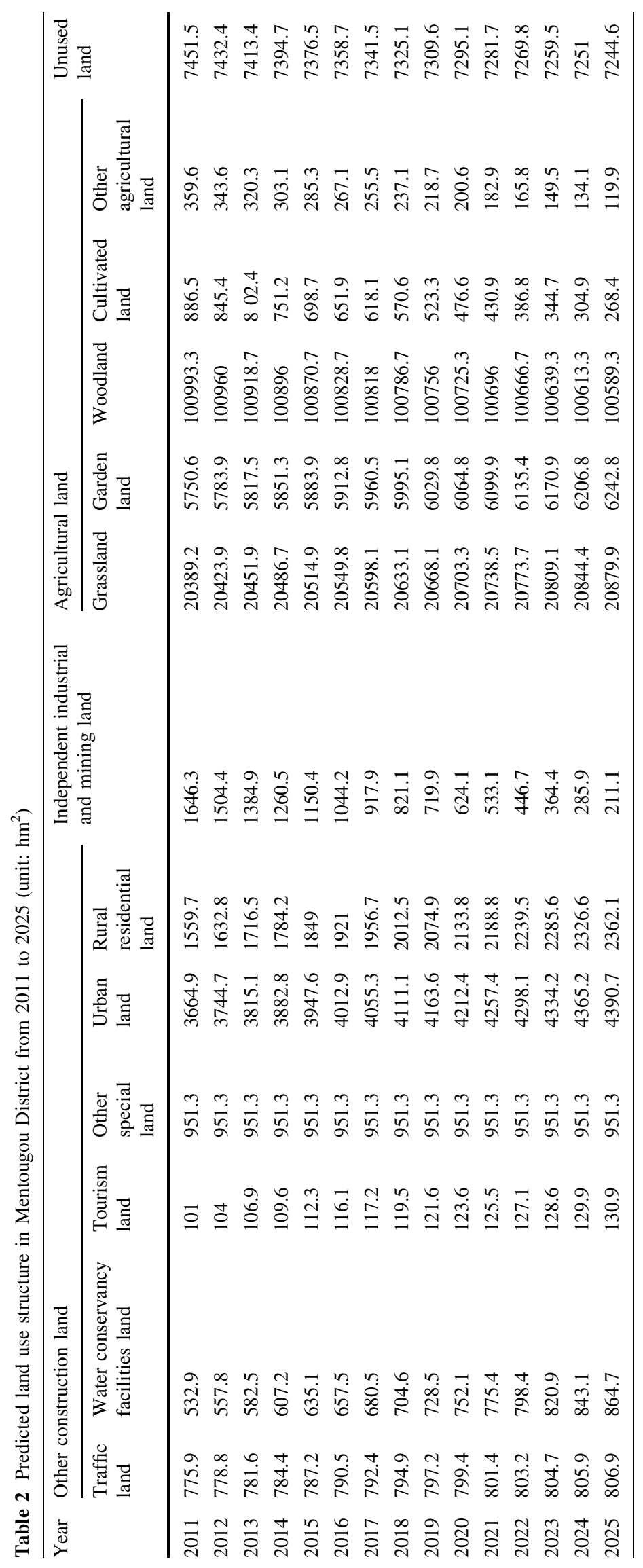



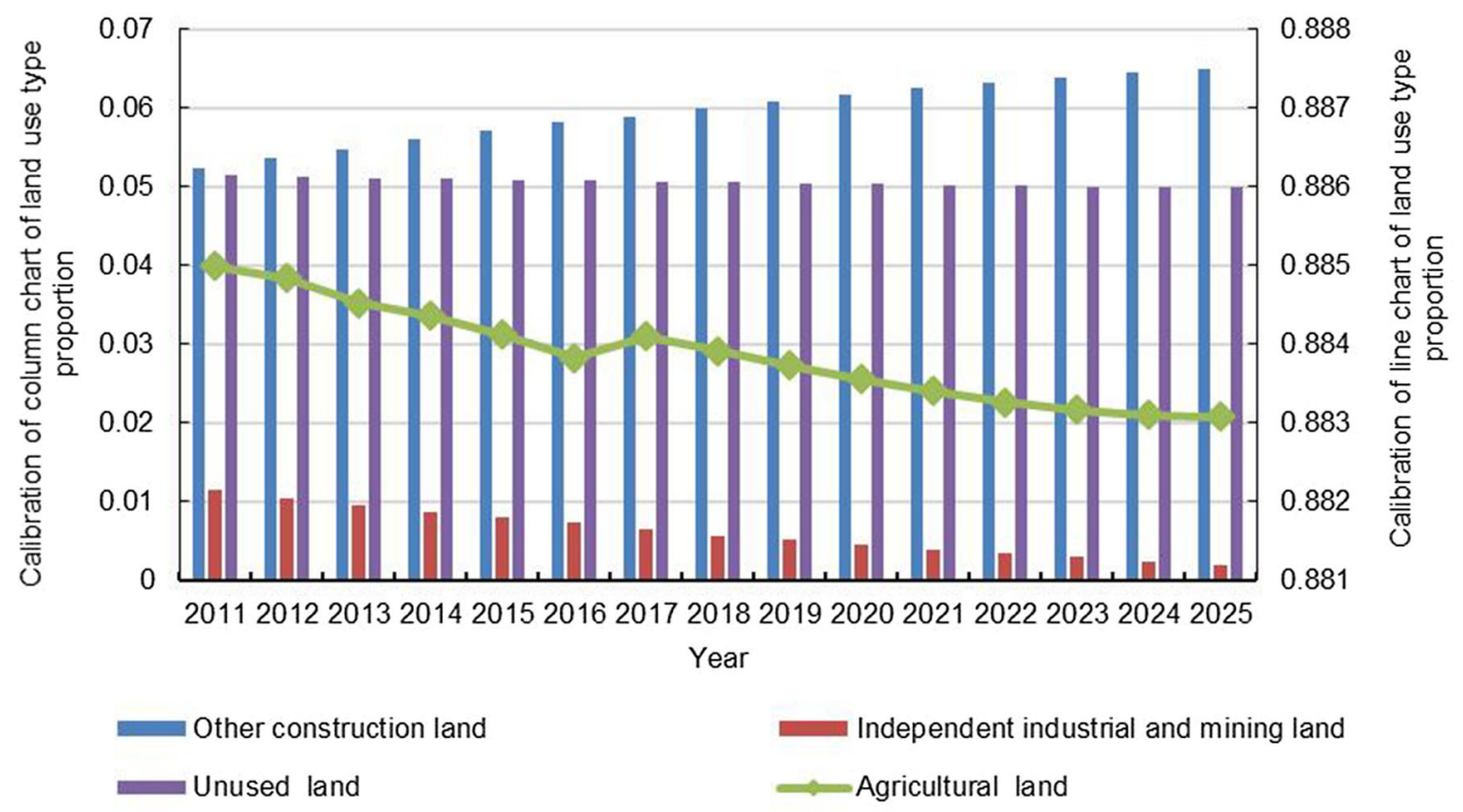

Fig. 4 Trend chart of proportion of land use types in Mentougou District from 2011 to 2025

calculation (Duan et al. 2006; Pan et al. 2010). The formula for calculating neighborhood enrichment factor is as shown in Formula 3.

$F_{i, k, d}=\frac{n_{k, d, i} / n_{d, i}}{N_{k} / N}$

where $F_{i, k, d}$ is the neighborhood enrichment factor; $i$ is the pixel position; $k$ is the land use type; $d$ is the neighborhood radius;

$n_{k, d, i}$ is the number of pixels of land use type $k$ within the radius $d$ of pixel $i ; n_{d, i}$ is the total number of pixels $i$ within the radius $d ; N_{k}$ is the pixel number of land use type $k$ in the research area; $N$ is the total pixel number in the research area. $F_{i, k, d}$ reflects the neighborhood enrichment degree of land use type $k$ within neighborhood $d$ in pixel $i$. If $F_{i, k, d}$ is less than 1 , it indicates that this neighborhood enrichment degree is less than that of the study area; if $F_{i, k, d}$ is equal to 1 , it indicates that this neighborhood enrichment degree is equal to that of the study area; if $F_{i, k, d}$ is greater than 1 , it indicates that this neighborhood enrichment degree is greater than that of the study area, and land use type $k$ tend to be enriched in this neighborhood.

Neighborhood interaction factor describes the mutual aggregation or exclusion characteristics between different land types. If there is no aggregation or exclusion, the neighborhood interaction factor is equal to 1 ; if two kinds of land type are mutually exclusive, the neighborhood interaction factor is less than 1; if two kinds of land type are aggregated, the neighborhood interaction factor is

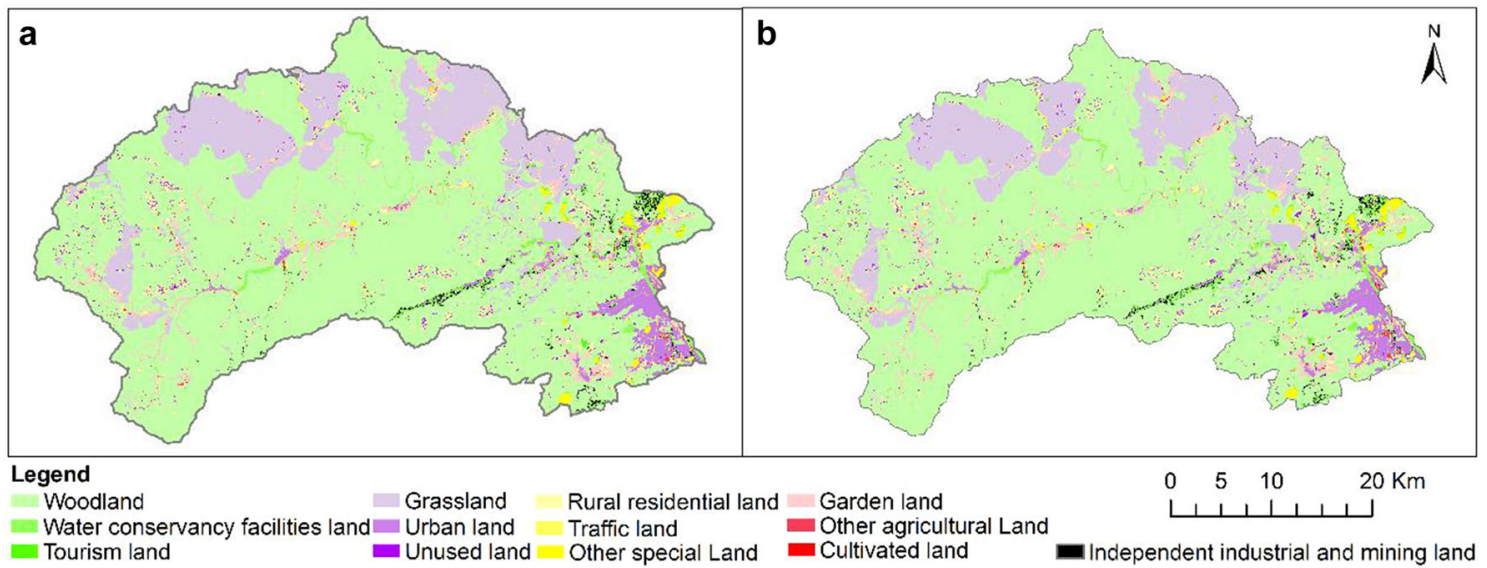

Fig. 5 Land use status (a) and simulation results (b) of Mentougou District in 2015 
greater than 1 . The formula for calculating neighborhood interaction factor is Formula 4.

$\bar{F}_{l, k, d}=\frac{1}{N_{l}} \sum_{i \in L} F_{i, k, d}$

where $\bar{F}_{l . k . d}$ is the neighborhood interaction factor; $l$ is the central land use type; $k$ is the land use type of the neighborhood; $i$ is the pixel position; $d$ is the neighborhood radius; $N_{l}$ is the total pixel number of the central land use type in research area; $\sum_{i \in L} F_{i, k, d}$ is the sum of the neighborhood enrichment degree value of the land use type $k$ within the radius $d$ of the central land use type $l$.

\section{Results and analyses}

\subsection{Time characteristics of land use structure in Mentougou District based on system dynamics model}

Taking the land use status data in 2010 as the basic period data, the predicted land use structure of Mentougou District is shown in Table 2 with the step value is $1 \mathrm{a}$. Combined with Fig. 4, it can be seen that land use structure in Mentougou District is still dominated by agricultural land from 2011 to 2025, but gradually adjusted: independent industrial and mining land decreased from 1646.3 to $211.1 \mathrm{hm}^{2}$ year by year because of the gradual closure of a series of mining enterprises such as Mentougou Coal Mine and Wangping Coal Mine in the study area from the end of 1990s, the gradual renovation of abandoned mine land, and the transformation of industrial and mining land to other industrial land by reclamation and reuse, which are in response to the depletion of mineral resources and the "ecological conservation development zone" plan proposed by Beijing (Cheng et al. 2014; Fan and Sun 2018; Li et al. 2017; Wang et al. 2007). The number of other construction land increased gradually and the growth rate was slowing down. Except for other special land, the number of each type of land increased gradually (Xie et al. 2017). The slowdown of the growth rate of other construction land was mainly due to the most stringent land management policy put forward by Beijing after the rapid development of urbanization from 1994 to 2005. The General Land-use Planning in Mentougou District, Beijing (2006-2020) proposed that by 2020, newly added construction land should not exceed $15533 \mathrm{hm}^{2}$ and the total scale should be limited to $10900 \mathrm{hm}^{2}$. With the decreasing of arable land and woodland, and the increasing of garden land and grassland, agricultural land decreased slowly in general. The internal change of agricultural land is mainly due to the adjustment of regional agricultural industrial structure. The General Land-use Planning in Mentougou District, Beijing (2006-2020) proposed that the development of orchard land should be based on the featured agricultural products such as Beijing white pear, rose and dried fruit in Mentougou district ( $\mathrm{Li}$ et al. 2010; Ren et al. 2018). Through various ecological projects, slope farmland can be returned to forest and grass, and forest and grass can be cultivated in mining area. Through intensive land use measures and ecological projects measures, independent industrial and mining land will be reduced, the growth of construction land and reduction of agriculture land will be effectively controlled, and the quality of local ecological environment will be further improved.

\subsection{Spatial optimization results and analysis}

\subsubsection{CLUE-S model test}

In order to control the simulation accuracy of CLUE-S model, historical data is usually used to verify the model (Mehdi et al. 2018; Sun et al. 2016; Xu et al. 2015;

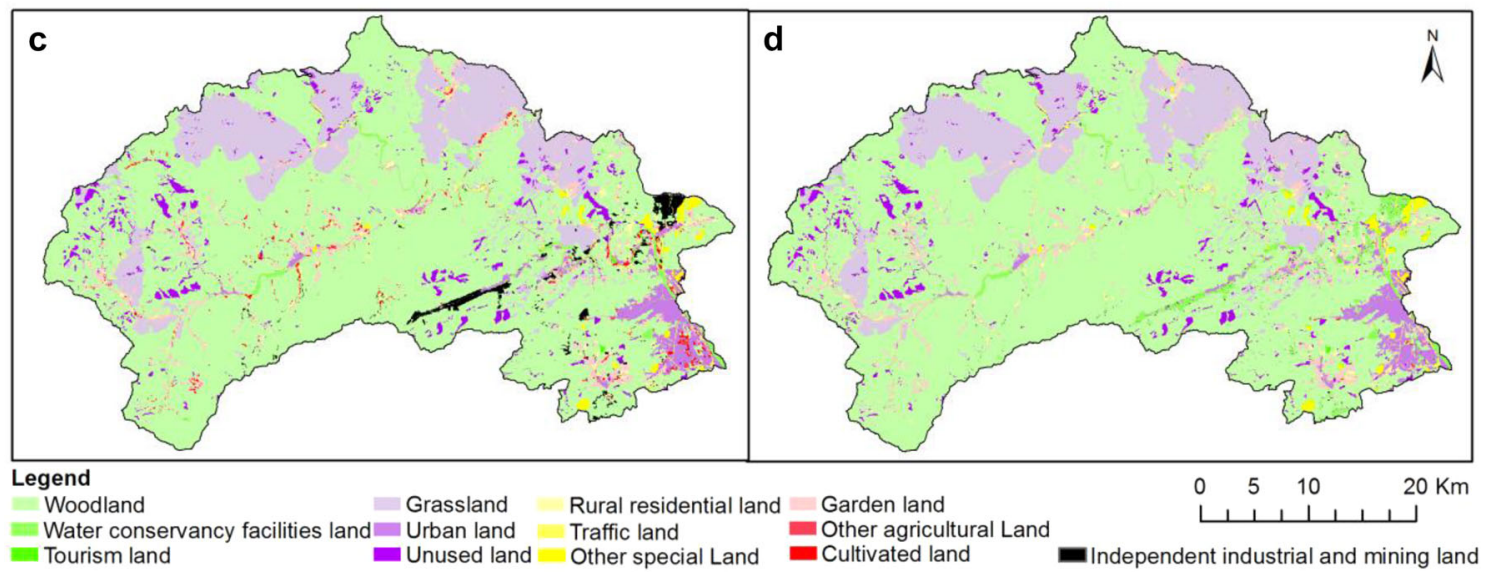

Fig. 6 Land use status of Mentougou District in 2010 (c) and simulated optimization results in 2025 (d) 


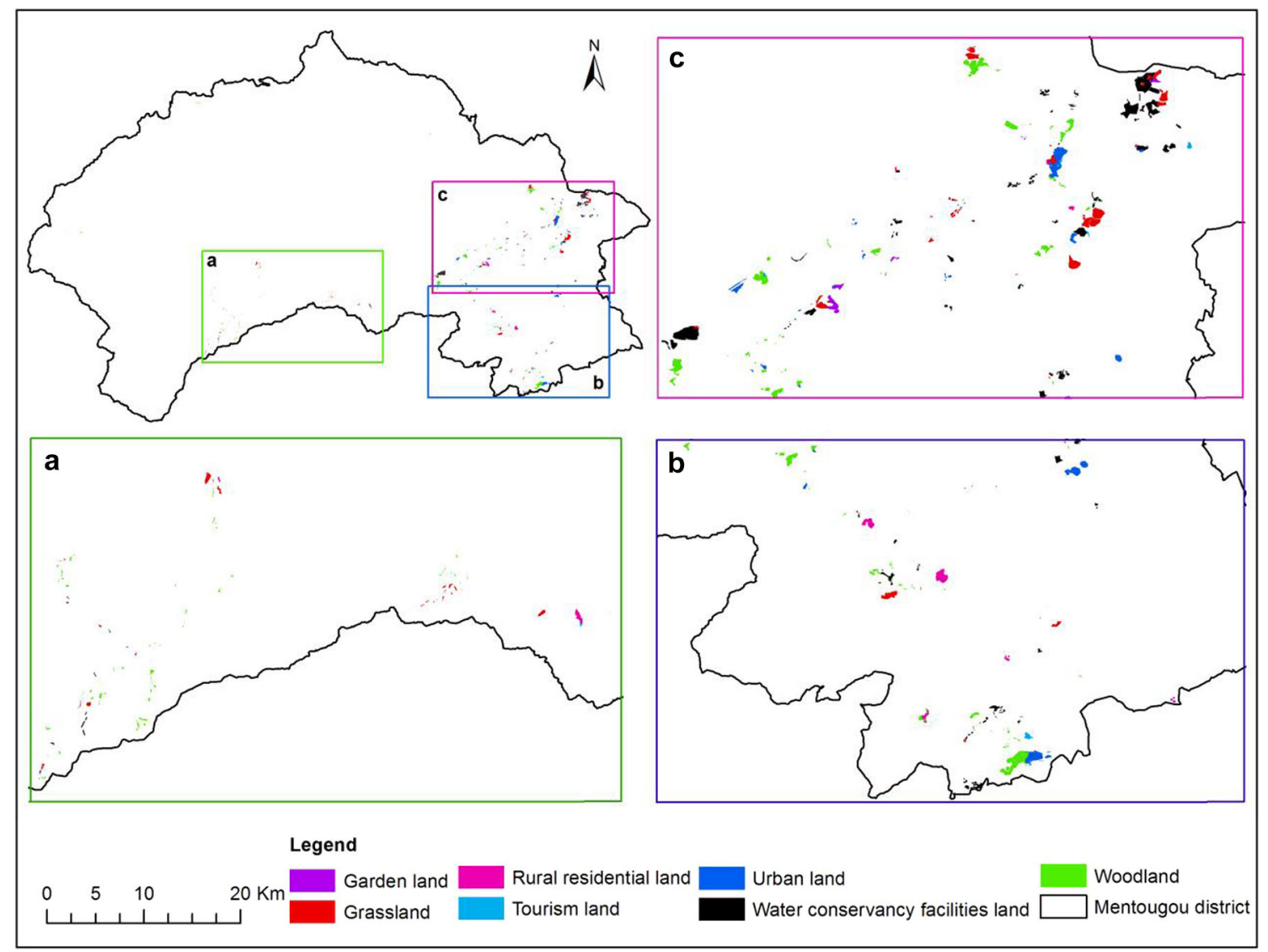

Fig. 7 The spatial structure optimization results of abandoned mine land reuse in Mentougou District

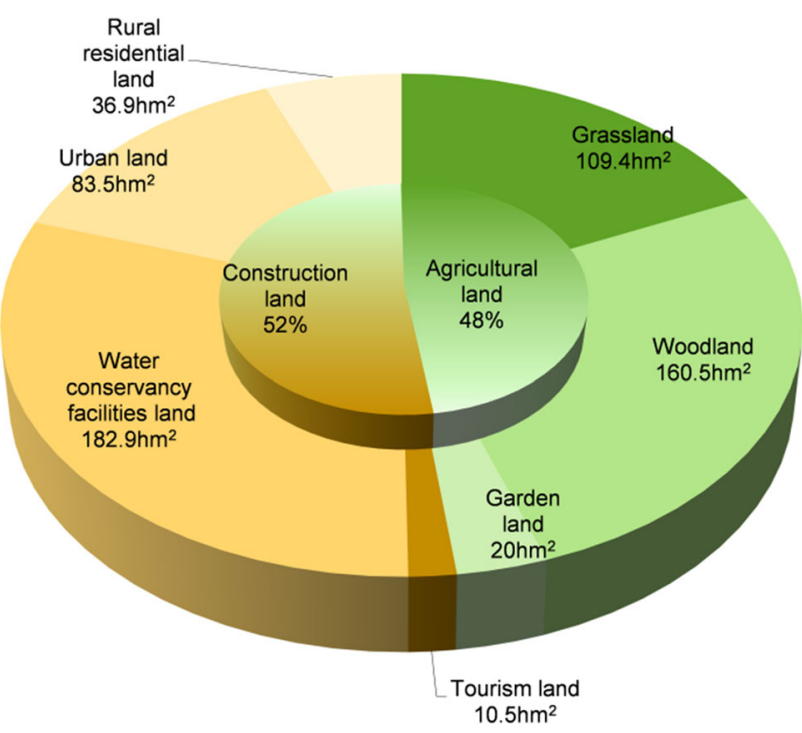

Fig. 8 Statistical chart of spatial structure optimization results of abandoned mine land reuse in Mentougou District

Yaghobi et al. 2017). In this paper, the raster map of land use status in 2010 was taken as the basic period data, and the simulated land use data in 2015 (Fig. 5b) was verified by comparison with the real land use status data in 2015 (Fig. 5a).

Kappa coefficient is usually used to evaluate the simulation accuracy of CLUE-S model (Jiang et al. 2015; Ren et al. 2018; Sun et al. 2016).After calculation, the Kappa coefficient between the land use simulation result obtained by CLUE-S model and the real land use status data in 2015 of Mentougou District is 0.89 ( $>0.81$ ), indicating the simulation result is well. Therefore, the use of CLUE-S model and the parameter setting in this paper are reasonable and reliable for simulating land use of Mentougou District in the future.

\subsubsection{Spatial optimization result of land use}

Taking the land use status data in 2010 as the initial state, the land use pattern of Mentougou District in 2025 was simulated and optimized, as shown in Fig. 6d, and the spatial pattern was compared with that of Mentougou District in 2010 (Fig. 6c).

In a relatively short period of time, the regional land use system is relatively stable (Xu et al. 2014). In future, forestland and grassland will still be the main land types in this area, and most of the urban construction land will be 
concentrated in the southeastern plain area, while rural settlements and towns will be scattered in low mountain areas. As the main driving force of regional land use change, policy and economy will promote the adjustment of land use structure and spatial pattern. By 2025, the transformation of independent industrial and mining land into forest land, grassland, water conservancy facility land and urban land and so on can promote the enhancement of regional water conservation capacity, improve the ecological environment, enhance the ecological barrier value and water conservation function of Mentougou District to the western part of Beijing, only leaving some sporadic patches of independent industrial and mining land. A large area of high-quality arable land will be reduced, and the reduced arable lands are mostly distributed near rural settlements and towns in plain areas. It suggests that the red line of regional cultivated land should be established, and the long-term effective system of regional cultivated land protection should be formulated, while the degree of intensive utilization of construction land required to be improved, and the idle land should be reclaimed.

\subsection{Optimization results of spatial structure of abandoned mine land reuse}

The optimization results of abandoned mine land reuse are obtained through the overlay analysis of abandoned mine land map and land use simulation map in 2025. The results are checked and revised according to the reuse suitability evaluation results. The final result is shown in Fig. 7. In order to analyze the optimization results intuitively, the statistical analysis tool of GIS is used and the result is shown in Fig. 8.

The optimization result shows that the spatial distribution of land use types in Mentougou District is more centralized and compact, and the spatial agglomeration degree of the same land use type is higher, meanwhile the sporadic patches of the abandoned mine land are easier to change into land use types of adjacent patches. By 2025, all the abandoned mine lands in Mentougou District can be reused as other land types according to land demands. About 52\% of the abandoned mine lands can be reused as construction lands, and about $48 \%$ can be reused as agricultural lands. Among them, about $36.9 \mathrm{hm}^{2}$ of abandoned mine lands are reused as rural residential lands, and $83.5 \mathrm{hm}^{2}$ of them are reused as urban land, while $10.5 \mathrm{hm}^{2}$ of them are reused as tourism lands. Most of these abandoned mine land are located at towns, rural settlements, tourism attractions or their neighborhoods. About $182.9 \mathrm{hm}^{2}$ of abandoned mine lands are reused as water conservancy facilities lands, and most of them are connected with other forms of independent industrial and mining lands, which is more conducive to improving water conservation capacity in Mentougou
District. About $20 \mathrm{hm}^{2}$ of abandoned mine lands are close to water area and have a certain distance away from towns and rural settlements, and they are reused as garden lands. The abandoned mine lands far from rural settlements are mostly used as grasslands and woodlands, of which the grassland is $109.4 \mathrm{hm}^{2}$ and the woodland is $160.5 \mathrm{hm}^{2}$.

\section{Discussion}

Most of the abandoned mine land distributed in large scale is usually directly reused as agricultural land or landscape land, and the technology has been gradually improved and matured (Holden 1999; McHarg 2006; Weilacher 1999; Shi 2013; Li et al. 2013; Li 2006; Thavamani et al. 2017). While there are numerous small mines widely distributed in China and small mining enterprises located in mountainous areas often produce fragmentary patches of abandoned mine land. Fragmented abandoned mine land is often left idle for the second time if it is directly reused as agricultural land or landscape land through restoration technology ( $\mathrm{Li}$ 2006; Li et al. 2018). The data of Mentougou District from 2006 to 2010 obtained by remote sensing images and field investigation showed that although the number of abandoned mine land decreased during this period, some of the reused abandoned mine land was re-idled due to unreasonable reuse. Abandoned mine land that has been left unused for the second time is less integrated with regional planning, and less consideration is given to land use types in neighboring areas. As a result, the phenomena of complex land use boundary, fragmentation of ecological landscape and unnecessary waste of land resources have not been improved, which hinders the flow of regional material and energy (Mekki et al. 2018), and it is also difficult to achieve effective management.

Some scholars try to use different methods to determine the reuse types of abandoned mine land (Gao and Bai 2018; Liu et al. 2016; Cheng et al. 2013) in order to realize rational use of land resources. However, most of the theoretical judgments focus on the reuse suitability evaluation under current conditions, ignoring how to achieve sustainable reuse under the dynamic evolution of land system. Abandoned mine land usually has multiple reuse suitability, for example, the same plot of land is suitable not only for agricultural land, but also for construction land, forest land, grass land etc. With the rapid development of social economy, the process of land use change intensifies, therefore, we should determine the most suitable reuse type of abandoned mine land from the overall and dynamic perspective. Compared with existing studies, this study simulated future land use situation based on social and economic development with the help of simulation model on spatial and temporal scale, and determined the reuse 
type of fragmented abandoned mine land according to future situation and the demand of the whole region, checked by reuse suitability evaluation. Abandoned mine land patches in mountainous area are scattered and small. Therefore, neighborhood analysis is fully taken into account when using CLUE-S model to allocate land use types spatially, thus avoiding the reuse of abandoned mine land as a fragmentary type. In this paper, the reuse type of abandoned mine land tends to be consistent with land use types in adjacent patches. This spatial feature is more in line with the geographical rule that the neighborhood of the same land use type is characterized by aggregation, which may be a process of imitating and learning from each other. Beijing has a typical north temperate semi-humid continental monsoon climate, but as a mega-city, it seriously lacks in water resources (Zhang and Lv 2018). The environment of Mentougou District was deteriorated and water resources were lost seriously because of mineral exploitation in the early stage. As an ecological conservation area in Western Beijing, the abandoned mine land adjacent to the independent industrial and mining land type is reused for water conservancy facilities, which is in line with the demand to restore water conservation function (Bai et al. 2011). The result can also be confirmed by Wang Shuang's simulation results of land use under the restriction of water resources in Beijing in 2020 (Wang et al. 2006).

Although it is of typical significance to select the system dynamics model and CLUE-S model based on the characteristics of the research object, further research is still needed. For example, CLUE-S model can simulate and predict the spatial pattern evolution of regional land use, but due to various constraints, the suitability of reusing abandoned mine land cannot be considered in all respects. Although the simulation results are tested and modified by the reuse suitability evaluation results, it may be more responsive to the requirements if the model can be further improved or modified by taking the evaluation results as the input parameters. In addition, there is still room for further research on the reuse of abandoned mine land. Similar to Mentougou, cities or districts with mining industry as the leading industry have a large number of abandoned mine land. On the other hand, due to the decline or exhaustion of mineral resources, these cities or districts urgently need industrial transformation to achieve sustainable development, and all the construction projects of industrial transformation need the support of land resources. It is undoubtedly a realistic way to ensure the future development of these cities or districts to reuse the widespread abandoned mine land optimally, tap the potential of land use and expand space for various construction projects. This article still fails to integrate the reuse of abandoned mine land with the industrial transformation of these cities or districts. How to make the reuse of abandoned mine land better serve the industrial transformation is the future research direction.

\section{Conclusion}

Due to the scattered nature of abandoned mountainous mine land, this paper combines CLUE-S model with system dynamics model to realize optimization of the spatial structure of the mountainous abandoned mine land reuse, making full use of the neighborhood analysis function of CLUE-S model and complex feedback function of system dynamics model. Case study of Mentougou District shows that the future land use pattern is still dominated by woodland and grassland, but the land use structure and spatial pattern are gradually adjusted. For example, the independent industrial and mining land is gradually transformed into other land types, and the area of other construction land types increase, while that of woodland and arable land reduce, and that of grassland and garden land increase. All the abandoned mine land can be reused as other land types according to land demand by 2025 . Among them, areas reused as water conservancy facilities land, urban land, rural residential land and tourist land are $182.9 \mathrm{hm}^{2}, 83.5 \mathrm{hm}^{2}, 36.9 \mathrm{hm}^{2}$ and $10.5 \mathrm{hm}^{2}$, respectively. Areas reused as grassland, woodland and garden land are $109.4 \mathrm{hm}^{2}, 160.5 \mathrm{hm}^{2}$ and $20 \mathrm{hm}^{2}$, respectively. Because of the neighborhood effect of land use and the fragmented patches of abandoned mine land, the reuse types of mountainous abandoned mine land tend to be consistent with land use types of adjacent patches.

Acknowledgements This study was supported by the National Natural Science Foundation of China (41877533) and Beijing Social Science Foundation (18GLB014).

\section{Compliance with ethical standards}

Conflicts of interest The authors declare no conflict of interest.

Open Access This article is distributed under the terms of the Creative Commons Attribution 4.0 International License (http://crea tivecommons.org/licenses/by/4.0/), which permits unrestricted use, distribution, and reproduction in any medium, provided you give appropriate credit to the original author(s) and the source, provide a link to the Creative Commons license, and indicate if changes were made.

\section{References}

Al-sharif AAA, Pradhan B (2014) Monitoring and predicting land use change in Tripoli Metropolitan City using an integrated Markov chain and cellular automata models in GIS. Arab J Geosci 7(10):4291-4301 
Anputhas M, Janmaat JA, Nichol CF, Wei X (2016) Modelling spatial association in pattern based land use simulation models. J Environ Manag 181:465-476

Bai Y, Wang R, Jin J (2011) Water eco-service assessment and compensation in a coal mining region-A case study in the Mentougou District in Beijing. Ecol Complex 8(2):144-152

Chen Q, Ling P, Xie Z (2008) Strategic decision-making model for adult higher college development based on system dynamics and its sensitivity analysis. Comput Aided Eng 17(1):67-71 (In Chinese with English abstract)

Chen C, Yu Z, Chen S, Zhang X (2017) System dynamics simulation of oil pipeline leakage under the consideration of emergency response. In: International conference on information management, pp 484-485

Cheng L, Skousen JG (2017) Comparison of international mine reclamation bonding systems with recommendations for China. Int J Coal Sci Technol 4(2):67-79

Cheng L, Lou S, Liu L et al (2013) Technology system and method of spatial structure optimization for mining wasteland reuse. Trans Chin Soc Agric Eng 29(7):207-218 (In Chinese with English abstract)

Cheng L, Li J, Xu Y, Lou S, Wang L, Sun S (2014) Determination of reclamation sequence for mining wasteland based on comprehensive evaluation. Trans Chin Soc Agric Eng 30(04):222-229 (In Chinese with English abstract)

Duan Z, Zhang F, Miao L (2006) Neighborhood-based method for land-use spatial pattern analysis and its application. Trans Chin Soc Agric Eng 22(6):71-76 (In Chinese with English abstract)

Fan W, Sun C (2018) Study on protection and development of coal industrial heritage tourism in Mentogou District of Beijing. China Coal 44(8):40-43 (In Chinese with English abstract)

Gao W, Bai Z (2018) Reuse ways selection of abandoned open pits based on inference conditions and rules. Trans Chin Soc Agric Eng 34(11):253-260 (In Chinese with English abstract)

Gao Z, Yi W (2012) Land use change in China and analysis of its driving forces using CLUE-S and Dinamica EGO model. Trans Chin Soc Agric Eng 28(16):208-216 (In Chinese with English abstract)

Gharbia SS, Alfatah SA, Gill L, Johnston P, Pilla F (2016) Land use scenarios and projections simulation using an integrated GIS cellular automata algorithms. Model Earth Syst Enviro 2:151

Gidey E, Dikinya O, Sebego R, Segosebe E, Zenebe A (2017) Cellular automata and Markov Chain (CA_Markov) modelbased predictions of future land use and land cover scenarios (2015-2033) in Raya, northern Ethiopia. Model Earth Syst Environ 3(4):1-18

Grossler A, Thun JH, Milling PM (2018) System dynamics as a structural theory in operations management. Prod Oper Manag 17(3):373-384

Gu C, Guan W, Liu H (2017) Chinese urbanization 2050: SD modeling and process simulation. Sci China Earth Sci 07:78-92 (In Chinese with English abstract)

Holden R (1999) International landscape architecture. Anhui Science \& Technology Publishing House, China Architecture \& Building Press, Anhui

Huang Y, Zhao M, Li W (2011) Establishment of free cash flow forecasting model based on trend extrapolation. Fiance Account Mon 3:59-61 (In Chinese with English abstract)

Jahanishakib F, Mirkarimi SH, Salmanmahiny A, Poodat F (2018) Land use change modeling through scenario-based cellular automata Markov: improving spatial forecasting. Environ Monit Assess 190(6):332

Jiang W, Chen Z, Lei X, Jia K, Wu F (2015) Simulating urban land use change by incorporating an autologistic regression model into a CLUE-S model. J Geogr Sci 25(7):836-850
Li MS (2006) Ecological restoration of mineland with particular reference to the metalliferous mine wasteland in China: a review of research and practice. Sci Total Environ 357(1-3):38-53

Li Q (2012) Research for simulation of urban land use change in Beijing by system dynamic model under water restriction from 2004 to 2020. Dissertation, Shanxi Normal University. (In Chinese with English abstract)

Li T, Qin Z, Li B, Gao C (2010) Research on eco-tourism of metropolitan type in mountain areas-take Wang Ping town, Mentougou District, Beijing as an example. Chin Agric Sci Bull 26(4):336-341 (In Chinese with English abstract)

Li H, Liu G, Fu B (2012) Estimation of regional evapotranspiration in alpine area and its response to land use change: a case study in three-river headwaters region of Qinghai-Tibet Plateau, China. Chin Geogr Sci 22(4):437-449

Li J, Tong J, Jiang SF, Nan L, Wang SJ, Wang J, Ye MC (2013) Water quality monitoring, early warning and identification of risk sources of South Lake Central Ecological Park in Tangshan City. Adv Mater Res 746:147-151

Li N, Zhong M, Zhao Z (2017) Beijing Mentougou coal mine reclamation of heavy metal contents in Chrysanthemum tea. Appl Chem Ind 46(09):1856-1858 (In Chinese with English abstract)

Li X, Yang H, Chen Z et al (2018) Literature review of redevelopment of abandoned mine land. Constr Technol 47(10):146-152

Liang D (2018) Situation review and development tendency outlook on world coal market in 2017. Coal Econ Res 38(03):6-18 (In Chinese with English abstract)

Liu M, Li C, Hu Y, Sun F, Xu Y, Chen T (2014) Combining CLUE-S and SWAT models to forecast land use change and non-point source pollution impact at a watershed scale in Liaoning Province, China. Chin Geogr Sci 24(5):540-550

Liu H, Liu Y, Rutian, Xu Y, Wang S (2016) Reuse type judgment of mining wasteland based on land use competitiveness [J]. Trans Chin Soc Agric Eng 32(10):258-266 (In Chinese with English abstract)

Lu Z (2012) Study on spatio-temporal optimization of sustainable regional land use -A case study of Jinan City. Dissertation, China University of Geosciences (Beijing). (In Chinese with English abstract)

Mao X, Meng J, Xiang Y (2013) Cellular automata-based model for developing land use ecological security patterns in semi-arid areas: a case study of Ordos, Inner Mongolia, China. Environ Earth Sci 70(1):269-279

McHarg LL (2006) Design with nature. Tianjin University Press, Tianjin

Mehdi B, Lehner B, Ludwig R (2018) Modelling crop land use change derived from influencing factors selected and ranked by farmers in north temperate agricultural regions. Sci Total Environ 631-632:407-420

Mekki I, Bailly JS, Jacob F et al (2018) Impact of farmland fragmentation on rainfed crop allocation in Mediterranean landscapes: a case study of the Lebna watershed in Cap Bon, Tunisia. Land Use Policy 75:772-783

Mishra VN, Rai PK (2016) A remote sensing aided multi-layer perceptron-Markov chain analysis for land use and land cover change prediction in Patna district (Bihar), India. Arab J Geosci 9(4):249

Mohammady M, Moradi HR, Zeinivand H, Temme AJAM, Yazdani MR, Pourghasemi HR (2018) Modeling and assessing the effects of land use changes on runoff generation with the CLUE-s and WetSpa models. Theor Appl Climatol 133:459-471

Moulds S, Buytaert W, Mijic A (2015) An open and extensible framework for spatially explicit land use change modelling: the lulcc R package. Geosci Model Dev 8(10):3215-3229 
Naboureh A, Moghaddam MHR, Feizizadeh B, Blaschke T (2017) An integrated object-based image analysis and CA-Markov model approach for modeling land use/land cover trends in the Sarab plain. Arab J Geosci 10(12):259

National Bureau of Statistics (2017) China land and resources statistics yearbook. Geological Publishing House, Beijing

Nobre Neto FD, Baptista CDS, Campelo CEC (2018) Combining Markov model and prediction by partial matching compression technique for route and destination prediction. Knowl-Based Syst 154:81-92

Olmedo CMT, Paegelow M, Mas JF, Escobar F (2018) Geomatic approaches for modeling land change scenarios. Springer, Berlin

Pan Y, Yu Z, Duan Z, Doluschitz R (2010) Influence of neighborhood distance on simulation accuracy of cellular automata model in land use. Trans Chin Soc Agric Eng 26(3):309-315 (In Chinese with English abstract)

Qi A, Holland RA, Taylor G, Richter GM (2018) Grassland futures in Great Britain-productivity assessment and scenarios for land use change opportunities. Sci Total Environ 634:1108-1118

Ren N, Wang S, Zhang F, Wang R, Mao S, Li Z (2018) Study on agricultural geological background of high-quality rose grown in Mentougou Mountain in Beijing. J China Agric Univ 23(07):107-115 (In Chinese with English abstract)

Shi X (2013) Spatial optimum allocation and management information system of mining wasteland reusing. Dissertation, China University of Mining \& Technology, Beijing. (In Chinese with English abstract)

Song XP, Hansen MC, Stehman SV, Potapov PV, Tyukavina A, Vermote EF, Townshend JR (2018) Global land change from 1982 to 2016. Nature 560(7720):639-643

Sun P, Xu Y, Yu Z, Liu Q, Xie B, Liu J (2016) Scenario simulation and landscape pattern dynamic changes of land use in the Poverty Belt around Beijing and Tianjin: a case study of Zhangjiakou city, Hebei Province. J Geogr Sci 26(3):272-296

Thavamani P, Samkumar RA, Satheesh V et al (2017) Microbes from mined sites: harnessing their potential for reclamation of derelict mine sites. Environ Pollut 230:495-505

Tian D, Fu B, Lv Y, Yang K, Che Y (2016) Effect of regional landuse change on soil organic carbon storage based on SD and CLUES-S model. Resour Environ Yangtze Basin 25(4):613-620 (In Chinese with English abstrct)

Waiyasusri K, Yumuang S, Chotpantarat S (2016) Monitoring and predicting land use changes in the Huai Thap Salao Watershed area, Uthaithani Province, Thailand, using the CLUE-s model. Environ Earth Sci 75(6):1-16

Wang Q (2009) System dynamics. Shanghai University of Finance \& Economics Press, Shanghai

Wang S, He CY, Pan YZ, Yang MC (2006) Research for scenarios simulation of urban land use change in Beijing by system dynamics model under water restriction from 2004 to 2020. J Nat Resour 21(4):535-544 (In Chinese with English abstract)

Wang D, Wang L, Zhu H, Gai H (2007) Ecological restoration function and ecological agricultural engineering plan in coal mining areas of Mentougou District, Beijing. Trans Chin Soc Agric Eng 23(11):138-142 (In Chinese with English abstract)

Wei W (2018) Land use optimal allocation based on CLUE-S and MCR model in Shiyang River Basin. Dissertation, Lanzhou University. (In Chinese with English abstract)

Weilacher U (1999) Between landscape architecture and land art. Springer, Berlin
Wu M, Ren X, Che Y, Yang K (2015) A coupled SD and CLUE-S model for exploring the impact of land use change on ecosystem service value: a case study in Baoshan District, Shanghai. China. Environ Manag 56(2):402-419

Wu Y, Li M, Liu L, Zhang Y, Liu L, Wang L (2017) Spatial-temporal allocation of regional land consolidation project based on landscape pattern and system dynamics. Clust Comput 20(4):3147-3160

Xie Z, Zhang T, Zheng Y, Zhou J, Gao Y (2017) Discussion on population-land-environment problem of Beijing based on nutrient balance. Trans Chin Soc Agric Eng 33(23):1-7 (In Chinese with English abstract)

Xiong Y, Yun C, Li J, Yan X (2018) Analog simulation of urban construction land supply and demand based on land intensive use. Acta Geogr Sin 73(03):562-577 (In Chinese with English abstract)

Xu Z, Coors V (2012) Combining system dynamics model, GIS and $3 \mathrm{D}$ visualization in sustainability assessment of urban residential development. Build Environ 47:272-287

Xu X, Gao Q, Peng C, Cui X, Liu Y, Jiang L (2014) Integrating global socio-economic influences into a regional land use change model for China. Front Earth Sci 8(1):81-92 (In Chinese with English abstract)

Xu QL, Yang K, Wang GL, Yang YL (2015) Agent-based modeling and simulations of land-use and land-cover change according to ant colony optimization: a case study of the Erhai Lake Basin, China. Nat Hazards 75(1):95-118

Yaghobi S, Faramarzi M, Karimi H, Sarvarian J (2017) Simulation of land-use changes in relation to changes of groundwater level in arid rangeland in western Iran. Int J Environ Sci Technol 1:1-12

Yang H, Wang G, Zhou L, Zhou R (2006) A study of power market dynamics based on system dynamics modeling. In: IEEE international conference on power system technology pp 1-6

Zhai H, Tang X, Wang G, Li J, Liu K (2018) Characteristic analyses, simulations and predictions of land use in poor mountainous cities: a case study in the central area of Chengde County, China. Environ Earth Sci 77(16):585

Zhang D (2013) Land use spatial-temporal change and simulation in mining city. Dissertation, China University of Geosciences (Beijing). (In Chinese with English abstract)

Zhang SF, Lv AF (2018) Research of effect on water resources carrying capacity in Beijing-Tianjin-Hebei region by water transfer. Resour Sci 40(11):2236-2246

Zhang Z, Feng L, Wang J (2012) Research on influencing factors of colliery flood based on system dynamics. Ind Eng $\mathbf{J}$ 15(2):128-133 (In Chinese with English abstract)

Zhao JS, Yuan L, Zhang M (2016) A study of the system dynamics coupling model of the driving factors for multi-scale land use change. Environ Earth Sci 75(6):529

Zheng XQ, Zhao L, Xiang WN, Li N, Lv LN, Yang X (2012) A coupled model for simulating spatio-temporal dynamics of landuse change: a case study in Changqing, Jinan, China. Landsc Urban Plan 106(1):51-61

Zhong H (2011) Study on land use changes and its effects on ecoenvironment in the Poyang Lake Region. Dissertation, Nanjing Agricultural University. (In Chinese with English abstract)

Zhou B, Xu Y, Vogt RD, Lu X, Li X, Deng X, Yue A, Zhu L (2016) Effects of land use change on phosphorus levels in surface waters-a case study of a watershed strongly influenced by agriculture. Water Air Soil Pollut 227(5):160 